\title{
Effects of nano and micro size of clay particles on the compressive and tensile strength properties of self- consolidating concrete
}

\author{
Baydaa Alrashedi ${ }^{1, *}$, and Maan Hassan ${ }^{1}$ \\ ${ }^{1}$ Building and Construction Engineering, University of Technology, 10066, Baghdad, Iraq
}

\begin{abstract}
Many past studies concerned about using of nanoclay $(\mathrm{nC})$ particles as an active pozzolan to concrete and their influence on the physical and mechanical properties. In this study, the effects of various nanoclay particle sizes and dosages on the compressive and flexural tensile strengths of SCCs were investigated. Progressive $\mathrm{nC}$ percentages of $2 \%, 5 \%$ and $8 \%$ were replaced with cements and the produced SCCs were evaluated and compared with similar replacement levels of the metakaolin MK which have comparable chemical compositions. The produced SCCs were tested for compressive, flexural tensile and splitting tensile strengths in 28 and 90 days. Results indicated that $\mathrm{nC}$ replacement harmed all the studied mechanical properties at 28 days age. After 90 days, however, both compressive and tensile strengths of $\mathrm{nC}$ concretes show superior strengths than control concrete and also exceeded MK concretes made of equivalent replacement levels. This behavior demonstrates the pozzolanic activity of the $\mathrm{nC}$ particles at later ages and proved to be significantly more effective than early ages.
\end{abstract}

\section{Introduction}

Self-compacting concrete (SCC) is an innovative concrete that does not require vibration for placing and compaction. It is able to flow under its own weight, completely filling formwork and achieving full compaction, even in the presence of congested reinforcement ${ }^{(1,2)}$. It was first launched in Japan in the late 1980's by Okamura to solve problems of pouring and setting concrete in high rebar densities structures ${ }^{(3)}$. The high workability of SCC results in a well compacted microstructure with reduced porosity in mortar matrix and interfacial zone, and thus, improves the electrical resistivity and transport properties of concrete. This is the key to enhanced durability performance of SCC ${ }^{(4)}$.

There are two ways of achieving SCCs, first by increasing the powder content, and second by incorporating chemical admixture. However, the chemical admixtures are expensive and their use may increase the cost of materials while the use of fine materials can ensure the required concrete properties without increasing the cost ${ }^{(5,6)}$.

Nanoclay (kaolin) is a fine, white, clay mineral that has been traditionally used in the manufacture of porcelain. Kaolinite is the mineralogical term that is applicable to kaolin clays. Kaolinite is defined as a common mineral, hydrated aluminum disilicate, the most common constituent of kaolin ${ }^{(7)}$.

Nowadays, in concrete design, concrete researchers and developers are taking advantage of secondary

*Corresponding author: baydaa.engineer@yahoo.com cementations materials to give concrete greater strength. One of the newest technologies to break into the concrete design is the use of pozzolanic nano-particles in the concrete matrix. By using pozzolanic nano-particles, the development of the strength bearing crystals of cement paste can be increased or controlled ${ }^{(8)}$

Nanotechnology is a very active research field and has applications in a number of areas. Currently this technology is being used for the creation of new materials, devices and systems at molecular, nano- and micro-level ${ }^{(10)}$. Nanoclay particles have shown promise in enhancing the mechanical performance, the resistance to chloride penetration, and the self-compacting properties of concrete and in reducing permeability. Clay and the properties of clay that are important as a mineral admixture to cement exist on the nanoscale, ${ }^{(11-15)}$.

In this study, two clay particle sizes: metakaolin (MK) and nanoclay (nC) were mixed in progressive replacement ratios with SCCs. The main aim was to assess the effects of nano size clay particles against alternative micro size metakaolin on the mechanical properties of SCCs. In terms of economical and industrial applications, the results of this study may provide more insights into the utilization of new but costly nanoscale mineral (i.e. nC) instead the more widely used MK.

\section{Experimental program}

\subsection{Preparation of raw material}


The preparation of raw material in this work is explained briefly in this section. Ordinary Portland cement (C) with trade mark of (Cresta) made in Iraq was used that conforms to Iraqi specifications number 5-2001 ${ }^{(16)}$. Fine aggregate (S) was brought from river sand and sieved using a $4.75 \mathrm{~mm}$ sieve to remove any possible large and clogging particles bigger than $4.75 \mathrm{~mm}$. Meanwhile, the $12 \mathrm{~mm}$ coarse aggregate $(\mathrm{G})$ was selected the grading curves conform to ASTM C33 $3^{(17)}$.

To maintain the freshness of SCC the sika based on modified polycarboxylic (viscocrete-5930) (SP) was used which conform to ASTM C 494 Type F. ${ }^{(18)}$. Table (1) shows the chemical composition of ordinary Portland cement, nanoclay(nC), kaolin (K), metakaolin (MK) and limestone powder (LSP) used in this study.

Table 1: Chemical composition of SCC fine materials

\begin{tabular}{|l|c|c|c|c|c|}
\hline constituent & $\mathrm{C} \%$ & $\mathrm{nC} \%$ & $\mathrm{~K} \%$ & $\mathrm{MK} \%$ & $\mathrm{LSP} \%$ \\
\hline silica & 21.9 & 38.64 & 50 & 49.64 & 1.12 \\
\hline Alumina & 4.97 & 13.15 & 32 & 10.7 & 0.64 \\
\hline Iron oxide & 3.2 & 2.25 & 1.4 & 3.7 & 0.3 \\
\hline
\end{tabular}

The nanoclay powder used in this study was a hydrophilic Montmorillonite materials. It was brought from (Nanocor ${ }^{\circledR}$ Inc, USA) and was used as received without any type of further treatment or manipulation. The Montmorillonites materials are high purity aluminosilicate minerals. It is sometimes referred to as phyllosilicates. Montmorillonites have a sheet-type or plate like structure. Even though their dimensions in the length and width directions have a scale of hundreds of nanometers, the plate thickness is only one nanometer. As a result individual sheets have aspect ratios ranging from 200-1000, with a majority of platelets in the 200400 range after purification. The theoretical formula for montmorillonite is:

$$
(\mathrm{Na}, \mathrm{Ca})_{\mathrm{x}}(\mathrm{Al}, \mathrm{Mg})_{2}\left(\mathrm{SiO}_{10}\right)(\mathrm{OH})_{2} \cdot \mathrm{nH}_{2} \mathrm{O}
$$

No chemical treatment is needed for this type of nanoclay to be dispersed in water which makes it easy to use in both concrete and mortar preparation.

\subsection{Mixing and curing}

The ACI 237R-07 procedure was followed to design SCC mix. It provides a guideline for proportioning mixtures and makes use of batches as trial mixes and then adjust the proportions based on the fresh and hardened testing results. The mix proportions of the ingredients used in this study are kept constant and only the $\mathrm{nC}$ or $\mathrm{MK}$ contents were changed as a cement replacement by weight (see Table-2).

The typical batching sequence that has been used to minimize balling of fine materials as below ${ }^{(19):}$

1) Adding the coarse aggregates to the mixer with more than $50 \%$ of mix water and mixing for 1 minute; 2) after performing the dry mix for the powders (cement, limestone, nanoclay or microclay particles) followed by adding the fine aggregate to the previous ingredients and mixing for 1 minute. As mentioned by other researcher ${ }^{(20)}$ nano materials were vigorously dry mixed with cement for $30 \mathrm{~min}$ or more to disperse nano particles with cement; 3 ) adding remaining water with $1 / 3$ of SP and mix for $1{ }^{1 / 4}$ minutes after that adding the $2 \beta$ of the leftover of SP dosage with $2^{34}$ minute mix time; 4) the mixture is then discharged, tested and casted.

In the present study the above procedure was followed. The total mix time takes 5 minutes. The concrete was prepared using ordinary Portland cement with a partial replaced by $\mathrm{nC}$ and $\mathrm{MK}$. The ingredients were homogenized on mixer to assure complete homogeneity and then water was added. The molds used in this study were cubes of $(100 * 100 \mathrm{~mm})$ size and cylinders $(100 * 200 \mathrm{~mm})$ size. The samples were kept wet in molds, and then cured in water until testing age.

\section{Results and discussion}

\subsection{Compressive strength}

The compressive strength test was carried out using cubes (100mm) according to BS 1881: part 116-2004 ${ }^{(21)}$. The cubes tested by using (ELE) machine. The average of three cubes was recorded. This test was conducted at 28, 90 days of ages and presented in Table (4) and Fig. (1).

As can be seen, the compressive strength of concretes containing $\mathrm{nC}$ reduced at 28 days compared to control. Reduction rate was increased as the replacement percentages increased and reached a maximum reduction rate of $23.3 \%$ at $8 \% \mathrm{nC}$ replacement. In contrast, progressive replacement percentages of $\mathrm{MK}$ lead to improve the compressive strengths and the improvements were a function of the replacement values of MK. This could be attributed to the higher pozzolanic activity of MK particles due to burning process during the preparation stage. These results suggest that at early ages up to 28 days, the positive effect of clay particles burning overrides the effect of using lower particle size even if it is in nano scale. 
Table 2: Details of concrete mixes used in the present work $\left(\mathrm{kg} / \mathrm{m}^{3}\right)$

\begin{tabular}{|c|c|c|c|c|c|c|c|c|c|}
\hline Mixes & C & nC & MK & LSP & P & W/C & G & S & SP \\
\hline SCC & 400 & 0 & 0 & 100 & 500 & 192 & 840 & 840 & $\mathbf{4}$ \\
\hline SCC-nC2\% & 392 & 8 & 0 & 100 & 500 & 192 & 840 & 840 & $\mathbf{5}$ \\
\hline SCC-nC5\% & 380 & 20 & 0 & 100 & 500 & 192 & 840 & 840 & $\mathbf{6}$ \\
\hline SCC nC 8\% & 368 & 32 & 0 & 100 & 500 & 192 & 840 & 840 & $\mathbf{8}$ \\
\hline SCC- MK 2\% & 392 & 0 & 8 & 100 & 500 & 192 & 840 & 840 & $\mathbf{5}$ \\
\hline SCC- MK 5\% & 380 & 0 & 20 & 100 & 500 & 192 & 840 & 840 & $\mathbf{6}$ \\
\hline SCC- MK 8\% & 368 & 0 & 32 & 100 & 500 & 192 & 840 & 840 & $\mathbf{8}$ \\
\hline
\end{tabular}

$\mathrm{SCC}=$ self-consolidation concrete, $\mathrm{nC}=$ nanoclay, $\mathrm{MK}=$ metakoalin, $\mathrm{C}=$ cement, $\mathrm{p}=$ total powder,

$\mathrm{LSP}=$ limestone powder, $\mathrm{S}=$ sand, $\mathrm{G}=$ crushed gravel, $\mathrm{SP}=$ superplasticizer**

Table 3: Compressive strength test results for SCCs

\begin{tabular}{|c|c|c|c|}
\hline $\begin{array}{c}\text { Group } \\
\text { No. }\end{array}$ & $\begin{array}{c}\text { Mix } \\
\text { Description }\end{array}$ & \multicolumn{2}{c|}{$\begin{array}{c}\text { Compressive } \\
\text { strength (MPa) }\end{array}$} \\
\hline \multirow{3}{*}{ Control } & & 28 days & 90 days \\
\hline \multirow{3}{*}{1} & SCC & 33.4 & 44.2 \\
\hline \multirow{3}{*}{2} & SCC-nC2\% & 33.1 & 49.2 \\
\cline { 2 - 4 } & SCC-nC5\% & 30.1 & 51.7 \\
\cline { 2 - 4 } & SCC-nC8\% & 25.6 & 54.1 \\
\hline & SCC- MK 2\% & 34 & 47 \\
\cline { 2 - 4 } & SCC- MK 5\% & 43.4 & 49.4 \\
\cline { 2 - 4 } & SCC- MK 8\% & 53 & 52.6 \\
\hline
\end{tabular}
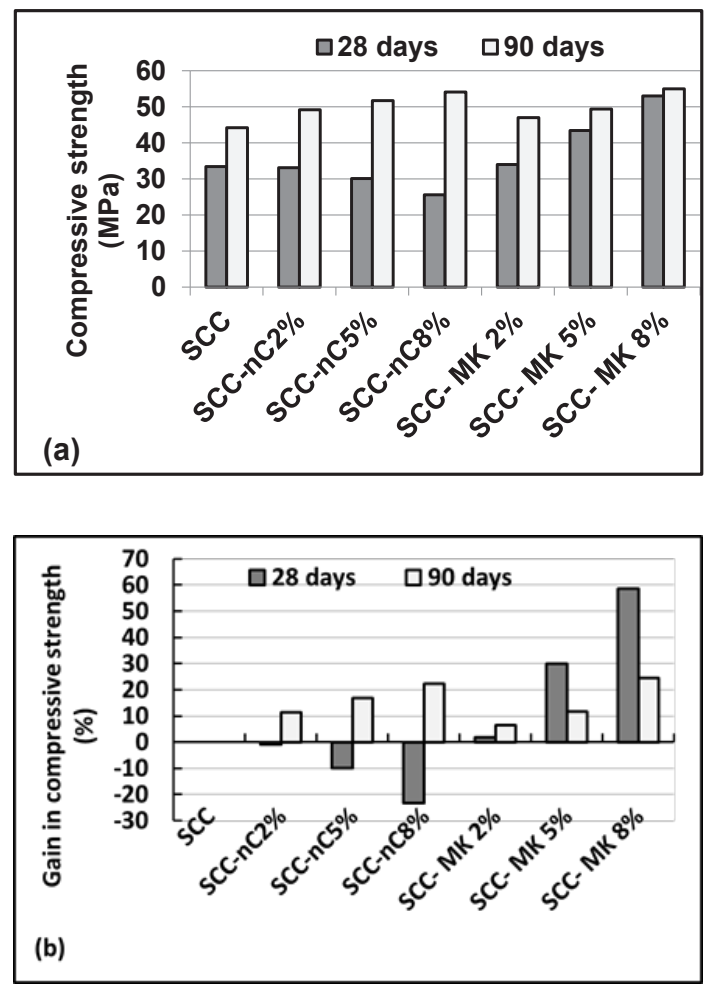

Fig. 1. Compressive strengths for SCCs contained MK and $\mathrm{nC}$ at 28 and 90 day (a) and gain in strengths (b)

At later ages (90 days), however, compressive strength of concretes containing $\mathrm{nC}$ particles observed to have higher level compared to control and also exceeded concretes of similar replacement percentages of MK. The gain in strength reached $22 \%$ at $8 \%$ replacement value. These results reflect the beneficial effect of nano scale particles at later time. They also illustrate the slow reaction rate of nonburned clay particles to actively participate in improving the cement past microstructure through better pore refinement, more consumption of $\mathrm{Ca}$ $(\mathrm{OH})_{2}$, micro filling action, and higher pozzolanic reactions.

To explain the differences in gain of strengths due to using $\mathrm{nC}$ against MK SCCs in this study, the ratios of 90 days to 28 days are presented in Fig. 2 below. In the case of $\mathrm{nC}$ concretes, the ratios increased as the percentages of replacement increased indicating higher activity in later ages compared with earlier ages. In the case of MK concretes, however, $90 \mathrm{~d} / 28$ $\mathrm{d}$ ratios of similar replacement levels were less than $\mathrm{nC}$ concretes indicating that concretes made with $\mathrm{MK}$ reached their maximum rate of strength at ages up to 28 days. After 90 days they almost became of constant level of strength and no more gains are achieved.

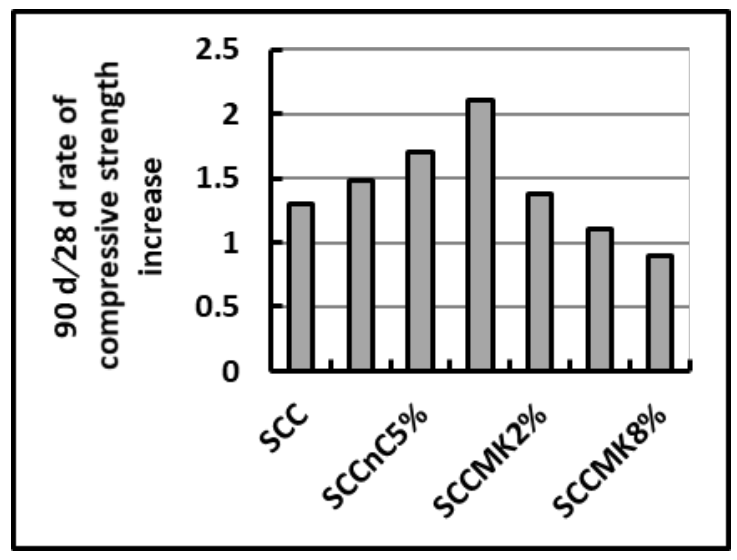

Fig. 2. Ratios of increase in compressive strengths (90 d/ 28 d) for SCCs with MK or nC cement replacements. 


\subsection{Tensile strength results}

The splitting and flexural tensile strength tests were carried out according to ASTM C496-2004(22) and ASTM C1609 ${ }^{(23)}$ respectively, at ages of 28, and 90 days. The results are shown in Table 4 and presented in Figs. 3 and 4.

Table 4: Splitting and flexural strength test results for SCCs.

\begin{tabular}{|c|l|l|l|l|l|}
\hline $\begin{array}{l}\text { Group } \\
\text { No. }\end{array}$ & $\begin{array}{l}\text { Mix } \\
\text { Description }\end{array}$ & \multicolumn{2}{|l}{$\begin{array}{l}\text { Splitting strength } \\
(\mathrm{MPa})\end{array}$} & \multicolumn{2}{l|}{$\begin{array}{l}\text { Flexural strength } \\
(\mathrm{MPa})\end{array}$} \\
\hline & & 28 days & 90 days & 28 days & 90 days \\
\hline \multirow{3}{*}{ Control } & SCC & 2 & 2.4 & 2.9 & 2.9 \\
\hline \multirow{3}{*}{1} & SCC-nC2\% & 1.8 & 2.7 & 2.7 & 3 \\
\cline { 2 - 6 } & SCC-nC5\% & 1.8 & 2.7 & 2.6 & 3.7 \\
\cline { 2 - 6 } & SCC-nC8\% & 1.9 & 2.8 & 2.6 & 3.9 \\
\hline \multirow{4}{*}{2} & SCC-MK 2\% & 2.0 & 2.5 & 3 & 3.1 \\
\cline { 2 - 6 } & SCC- MK5\% & 2.3 & 2.7 & 3.1 & 3.4 \\
\cline { 2 - 6 } & SCC-MK 8\% & 2.5 & 2.7 & 3.5 & 3.8 \\
\hline
\end{tabular}

In general, the incorporation of nanoclay particles into concrete cement past led to reduction in both splitting and flexural tensile strengths for all SCC specimens at 28 days ages, as shown in Figs. 3 and 4, respectively. The addition of $2 \%, 5 \%, 8 \%$ nanoclay reduced splitting strength by $10 \%, 10 \%, 5 \%$; and flexural strength by $7 \%, 10 \%, 10 \%$, respectively, compared to control specimens. The reduction in mechanical properties can be attributed to the poor dispersion and agglomeration of the nanoclay in the cement paste at higher replacement percentages. Other researchers reported that nanoclay contents more than $1 \%$ could create weak zones in the form of micro voids as stress concentrators ${ }^{(24-28)}$. This behavior is correlated with the compressive strength results.
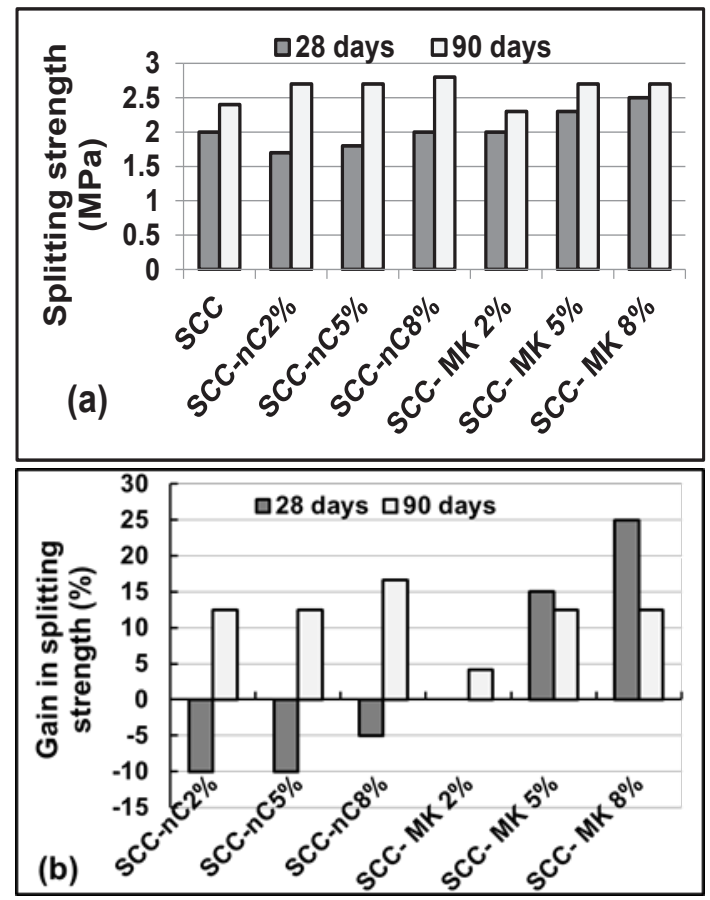

Fig. 3. Splitting strengths for SCCs contained $\mathrm{MK}$ and $\mathrm{nC}$ at 28 and 90 day (a) and gain in strengths (b)
After 90 days, both splitting and flexural tensile strengths were increased. Progressive values of $\mathrm{nC}$ replacements resulted in enhancements in tensile strengths of the investigated SCCs.

The use of MK led to noticeable improvement in both 28 and 90 days. Concretes with $2 \%, 5 \%, 8 \%$ MK replacement have $0 \%, 15 \%, 25 \%$ higher at 28 days and $4 \%, 12.5 \%, 12.5 \%$ higher at 90 days of splitting strengths, respectively. The improvement in flexural strengths in similar replacement levels were $3 \%, 7 \%$, $20 \%$ higher at 28 days and $7 \%, 17 \%, 31 \%$ higher at 90 days, respectively. The results suggest that using $\mathrm{nC}$ with cementitious materials may reduce early ages strengths in comparison to MK, but it could have significant improvements during the next few months and even exceed the MK improvement rates.
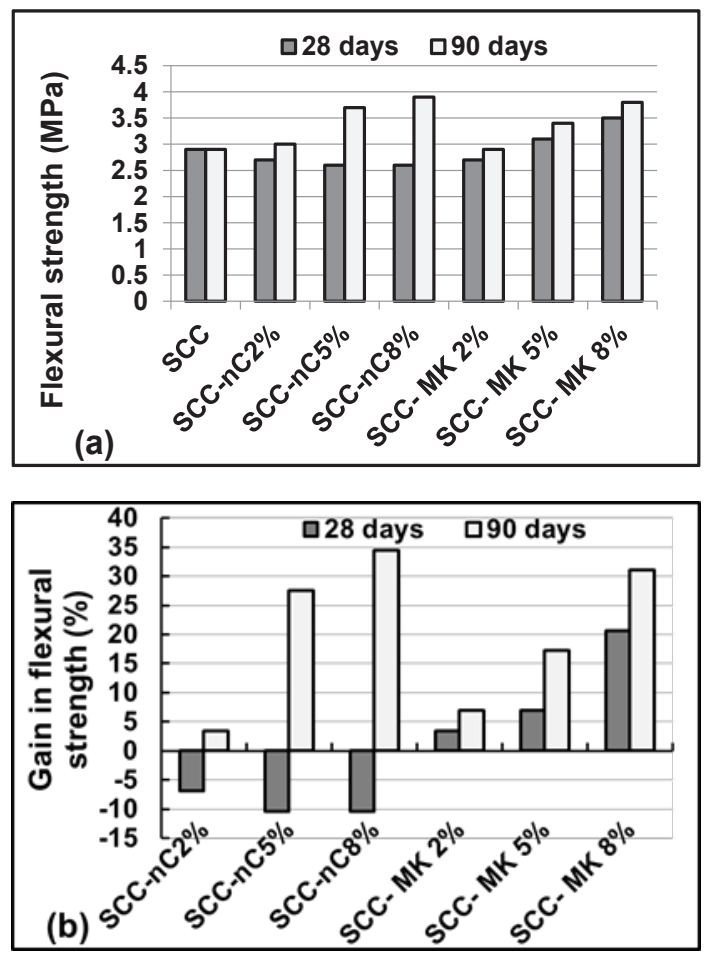

Fig. 4. Flexural strengths for SCCs contained $\mathrm{MK}$ and $\mathrm{nC}$ at 28 and 90 day (a) and gain in strengths (b)

\section{Conclusions}

Based on the experimental work results in this research work, the following conclusions can be drawn:

1. For all SCCs, progressively higher cement percentage replacements from $2 \%$ to $8 \%$ of $\mathrm{nC}$ led to significant reduction in the compressive and tensile properties at 28 days age. The reduction was proportioned to the percentage of the cement replacement. On the contrary, use of metakaolin led to enhancement of the compressive and tensile properties at the same dosages and similar age. 
The low pozzolanic activity of $\mathrm{nC}$ at early ages up to 28 days is probably behind this reduction.

2. At later age (i.e. 90 days), both concretes made with $\mathrm{nC}$ or MK showed remarkable increase in the compressive and tensile properties. The gain in strengths of $\mathrm{nC}$ concretes was more visible, and the level of strengths exceeded the MK concretes made with equivalent replacement levels.

3. Among various $\mathrm{nC}$ and $\mathrm{MK}$ dosages used, $8 \%$ provided the better later age strength achieved.

Acknowledgments: The authors would like to thank the Building and Construction Engineering Department of University of Technology, Baghdad, Iraq, for extending the facilities and laboratories for the above research work.

\section{References}

1.Okamura,H., and Ouchi,M., Journal of Advanced Concrete Technology Vol. No.1, PP.5-15, April(2003).

2. EFNARC,The European Federation of Specialist Constructionand Concrete System, pp.63, May, (2005).

3. Borroni, M., Proceedings of the $2^{\text {nd }}$ FIB international congress, Naples, Italy, pp. (1-7), (2006).

4. Safiuddin, Md., West, J.S., and Soudki, K.A, Journal of Applied Sciences Research, Vol.4, No.12, pp.(1834-1840),(2008).

5. Tregger NA,Pakula ME,Shah SP, Cem Concr Res 40 (Compendex):384-91, (2010).

6. Ferron R., PhD Thesis, Northwestern University, Evanston, IL; (2008).

7. Rafat Siddique, Department of Civil Engineering, Thapar University,India, (2008).

8. Jonathan S. Belkowitz and Daniel Armentrout, Concrete Sustainability Conference, PP(1-14), (2010).

9. Syeda A. Yousaf and Salamat Ali, Journal of Faculty of Engineering \& Technology, PP (11, 12), (2007-2008).

10. Perumalsamy B. and Ken Ch, Proceedings of ACI Session on "Nanotechnology of Concrete: Recent Developments and Future Perspectives", Denver, USA, PP (15), 7 November, (2006)

11. Florence S.,\& Konstantin S, Construction and Building Materials, 24 (11), (2010).

12. Chang T-P, Shih J-Y, Yang K-M, Hsiao T-C, J Mater Sci;42(17), PP.(7478-87), (2007).

13. Kuo W-Y, Huang J-S, Lin C-H., Cem Concr Res;36(5) ,PP.(886-95),(2006).

14. Morsy MS, Aglan HA, Abd El Razek M. M., Construct Build Mater; 23(1), PP. (515-21), (2009).

15. He X, Shi X., Transport Res Board Record: J Transport Res Board (2070), PP. (13-21), (2008).
16. Iraqi Standard No. (5) for the year 2001, "Portland Cement" 16. The Central Agency for Standardization and Quality Control.

17. ASTM C33/C33M-13, American Society for Testing and Material International, (2013).

18. ASTM C494-99a, Annual Book of ASTM Standards, American Society for Testing and Materials, Vol. 04-02,(2004).

19. R.T. Abdulkareem, M.S. Hassan, I.N. Gorgis, Eng. \& Tech. Journal. 34: 527-538, (2016).

20. Farzadnia, N., Ali, A. A. A., Demirboga, R., and Anwar, M. P., Cement and concrete research, 48,(2013).

21. B.S 1881: Part 116, British Standards Institution,(1989).

22. ASTM C496-04, American Society for Testing and Materials, 2004.

23. ASTM C1609M - 12, American Society for Testing and Material International, (2012).

24. Morsy MS, Alsayed SH, Aqel M., Constr Build Mater;25(1):145-9,(2011).

25. Li H, Xiao H, Yuan J, Ou J., Composites Part B; 35(1):185-9,(2004).

26. A. Hakamy a, FUA Shaikh b, I.M. Low. Construction and Building Materials 49 ,298307,(2013)

27. M.S. Hassan, I.N. Gorgis and Ali A. Jaber ARPN Journal of Engineering and Applied Sciences.12 (17), (2017).

28. M.S. Hassan, Z.M. Al-azawi, M.J. Taher., Arab. J. Sci. Eng. 41. (2016). doi:10.1007/s13369-016-2056-Z. 